\title{
GOVERNANÇA CORPORATIVA EM STARTUPS
}

\section{Amanda Maia Ramalho ${ }^{1}$}

\section{RESUMO}

A busca por modelos de negócios inovadores tem preenchido o mercado com o aparecimento, crescimento e estruturação de startups. Inspiradas no modelo americano, as mesmas possuem forma de trabalho e buscam uma estruturação interna baseada em um informalismo ainda relativamente estranho ao ambiente negocial brasileiro, importando, por isso, em uma série de reflexos jurídicos indesejáveis que, por vezes, levam ao insucesso do negócio ainda em early stage. O presente artigo visa fazer algumas ponderações acerca da necessidade do amparo jurídico e da adequação da inovação ao Direito, atendendo, assim, a livre iniciativa, autonomia da vontade das partes e o princípio da preservação da empresa.

PALAVRAS-CHAVE: Startups. Governança Corporativa. Direito Empresarial. Mercado. Compliance.

\section{CORPORATE GOVERNANCE IN STARTUPS}

\begin{abstract}
The need for innovative business models has filled the market with the arising, growth and structuring of startups. Inspired by the american model, they have a form of work and seek an internal structure based on informalism that is relatively foreign to the brazilian business environment. even in early stage. This article aims to make some considerations about the need for legal protection and the adequacy of innovation to the law, taking into account the free initiative, the will of the parties and the principle of preservation of the company.
\end{abstract}

KEY-WORDS: Startups. Corporate Governance. Corporate Law. Business. Compliance.

\section{INTRODUÇÃO}

O conceito de startups não é próprio do Direito, ainda que muitos do meio jurídico venham apropriando-se do estudo e buscando defini-lo conforme seu entendimento. À vista disso, não guarda consenso, nem em seu meio próprio, nem no meio jurídico.

Conceituaremos, portanto, inicialmente o conceito que acreditamos ser o mais apropriado para fins acadêmicos e de discussão. Em seguida, seguiremos expondo algumas considerações jurídicas que visam adequar a realidade das startups ao sistema jurídico

\footnotetext{
1 Advogada. Mestre em Direito. Especialista em Compliance. Pós-graduanda em Direito Corporativo e Compliance. Professora do Centro Universitário do Estado do Pará (Direito Empresarial e Deontologia). Presidente da Comissão de Compliance da OAB/PA. amandaramalhoadv@gmail.com
} 
brasileiro, a fim de atender aos princípios da iniciativa, autonomia da vontade das partes e o princípio da preservação da empresa.

Em que pese esse consenso não ter sido até então encontrado, a Lei Complementar $\mathrm{n}^{\circ}$ 167/2019 trouxe o "Inova Simples" que acabou por conceituar o que se compreende por startups no ordenamento jurídico brasileiro.

Acreditamos ser importante atentar ao fato de que, a Ordem Econômica, prevista constitucionalmente no artigo $170 \mathrm{da} \mathrm{CF} / 88$ que garante a possibilidade de contratar de forma livre, aqueles em paridade de condições e que sejam aptos para tal.

Interessante atentar que, em relações de cunho privado, o Estado deve funcionar apenas como resguardo aos direitos das partes no caso de violação, não se presume que o Estado intervenha nessa relação, posto que as partes envolvidas possuem igualdade material (técnica e de compreensão).

Neste sentido, visa-se apresentar a importância da Governança Corporativa para o bom desenvolvimento dos modelos de negócios que sejam ou pretendam ser startups.

\section{STARTUPS COMO MODELO DE NEGÓCIO}

Antes de defender que startups são um modelo de negócio, que se diferencia por características muito claras e específicas de outros modelos, necessitamos apresentá-la, para, então, conceituar e defender o ponto de vista de que é um modelo de negócio.

Startup ${ }^{2}$ é comumente conceituada como sendo uma sociedade iniciante no mercado, criada e conduzida por jovens com ideias inovadoras e, ainda, vinculada à tecnologia. Seu objetivo segundo esse conceito, seria desenvolver suas ações com o maior lucro e o menor custo possível aos sócios.

O negócio pretendido por meio de uma startup pode criar algo ou novo, ou mesmo, melhorar algo existente, seja um produto ou um serviço. O objetivo maior é, ao fim, oferecer uma solução rápida e eficiente, ou um serviço diferenciado.

\footnotetext{
2 Inglês; substantivo; tradução "começar"; "iniciar". Também utilizado, a partir da bolha da internet, como o momento de início de alguma coisa, de colocá-la em andamento.
} 
O conceito que reputamos como mais adequado é aquele que, identifica startups como um modelo de negócio que, para se perfazer, precisa ter algumas características fundamentais, sem as quais, torna-se um modelo de negócio tradicional.

O que define, portanto, um negócio como sendo uma startup são exatamente essas características e não o tamanho do negócio (pequeno, médio ou grande), tão pouco, tem a ver com o seu momento (pode ser um negócio inicial, tanto quanto pode ser um negócio existente que se reinventa a partir das características que apresentaremos).

Cumpre atentar, ainda, antes de definir efetivamente o que vem a ser uma startup que esse conceito não é próprio do direito, e que, portanto, não cabe à nós operadores do Direito, pretendermos conceitua-los como bem entendemos, devendo, por outro lado, compreender a sua realidade jurídica, diante das suas especificidades.

À vista do exposto, para que um negócio seja assim considerado o mesmo precisa ter algumas características, quais sejam: inovação, ser repetível, escalável e disruptivo. Como dito acima, não são conceitos próprios do Direito e por isso vamos compreender melhor a partir da definição de cada um deles.

A inovação é o ato de criar algo novo, gerar novidade, promover uma mudança ou um aperfeiçoamento, logo, em uma startup isso pode se dar pela criação de um produto ou serviço totalmente novo, tanto quanto pelo melhoramento de um produto ou serviço já existente no mercado. Esse requisito é importante, porque deixa claro que um negócio inovador não requer necessariamente o ineditismo.

A título de exemplo, trazemos o aplicativo Airbnb, considerado pelo WallStreet Journal, como a $8^{\text {a }}$ (oitava) maior startup do mundo, avaliada em U\$10 bilhões, cuja atividade é possibilitar que pessoas normais possam alugar sua própria casa (ou parte dela, como um quarto ou cômodo) para outras pessoas, por meio de uma plataforma totalmente digital que permite ao usuário a visualização de fotos do ambiente a ser locado.

Ou seja, o Aribnb não inventou a hotelaria, mas inovou no conceito de hospedagem ao permitir a baixo custo que pessoas possam alugar espaços para estadia gerando, ainda, uma fonte de renda "extra" para quem deseja alugar um cômodo ou imóvel seu que esteja desocupado. 
Ser escalável e repetível, significa que aquele produto ou serviço, podem ser executados de forma repetida (e igual ou muito similar) e ganhe escalabilidade, que significa que o negócio tem a capacidade de manipular uma porção crescente de trabalho de maneira uniforme.

Isso significa, ainda que com o seu lucro, o negócio terá capacidade de mudar de porte (passando de pequena ou média empresa, para um grande negócio) em curto espaço de tempo.

O modelo "enxuto" permite que esse tipo de negócio gire com o mínimo de custos fixos, e o máximo de eficiência, e, portanto, o máximo de lucro, que é o garante este segundo e terceiro ponto.

A disrupção significa quebra ou descontinuação de um processo já estabelecido, é algo que interrompe, suspende e afasta o funcionamento de algo como se conhecia e convida a uma remodelação.

Esse fenômeno, de quebra de padrões, é o meio pelo qual negócios passam a oferecer novas alternativas de produtos ou serviços, de forma mais parada, usualmente mediante o emprego da tecnologia, otimizando os processos, ou seja, estabelecem novos métodos que se afastam dos modelos já estabelecidos no mercado. Utilizam o famoso "pensar fora da caixa".

Para melhor compreensão, elucida Eric Ries (2012, p. 26):

Uma startup é uma instituição humana projetada para criar novos produtos e serviços sob condições de extrema incerteza. Passei a perceber que a parte mais importante dessa definição é o que ela omite. Não diz nada a respeito do tamanho da empresa, da atividade ou do setor da economia. Qualquer pessoa que está criando um novo produto ou negócio sob condições de extrema incerteza é um empreendedor, quer saiba ou não, e quer trabalhe numa entidade governamental, uma empresa apoiada por capital de risco, uma organização sem fins lucrativos ou uma empresa com investidores financeiros decididamente voltada para o lucro.

E ainda:

A startup is an institution, not just a product, and so it requires a new kind of management specifically geared to its context of extreme uncertainty. In fact, as I will argue later, I believe "entrepreneur" should be considered a job title in all modern companies that depend on innovation for their future growth. (RIES, 2011, p. 18 e 19$)^{3}$

\footnotetext{
${ }^{3} \mathrm{~A}$ startup é uma instituição, não apenas um produto, e por isso requer uma nova forma de organização especificamente para esse contexto de extrema incerteza. De fato, como concordaremos
} 
As startups chamam atenção do meio jurídico, por buscar inovar em todos os campos, incluindo na forma como as pessoas que dela fazem parte fazem negócio, desde a forma como contratam, até a forma como pretendem vender.

Isso significa o Direito precisa entender, analisar e, naquilo que for possível se reinventar para poder atender as demandas emergentes que vem destes empreendedores que, invariavelmente, necessitarão de formalização dos seus negócios para a obtenção dos resultados que almejam.

Sua constituição, estruturação e desenvolvimento deve ser baseado em uma forte proteção às partes envolvidas, considerando os terceiros com quem pretendem fazer negócios, dada a natural e inerente condição de incerteza que se tem ao instituir este modelo.

O crescimento de uma sociedade que adota o modelo de startup está proporcionalmente relacionado com a inovação do serviço prestado, o qual the garante um possível crescimento futuro de forma extremamente rápida.

O contexto de incerteza do instituto e nas relações tensas e divergentes que podem surgir desta relação, que o tema também chama a atenção do Direito, que, nesses casos, deve se fazer presente na tentativa de solucionar os conflitos e na procura pela proteção dos direitos conferidos a fim de que o conflito não se concretize, principalmente, no tocante ao ramo do direito empresarial, os princípios que o regem e às lições sobre o direito societário.

É importante atentar nesse contexto que esses empreendedores não se identificam com o modelo tradicional de fazer negócio e não querem ser considerados ou se relacionar da mesma forma que os empresários fazem, porém, por mais que não queiram perpetuar uma prática de mercado que consideram ultrapassada, não podem escapar a uma situação: startups são, querendo os empreendedores ou não, sociedades empresárias.

Não cabe a eles (empreendedores) a faculdade de escolher proceder ou não com as obrigações inerentes a todos os tipos de empresários, sejam eles empresários individuais ou pessoas jurídicas. Para exercerem regularmente as atividades que pretendem, sob o modelo de

mais tarde, eu acredito que "entrepreneur" deve ser considerado um título de emprego em todas as companhias modernas que dependem de inovação para o seu futuro crescimento. (Tradução Livre). 
negócio que escolheram, estes precisam proceder o registro da sua atividade em órgão competente, escolher nome empresarial, compreender os deveres de escrituração, entre outros.

O profissional que se destaca frente à essa realidade de cliente é aquele que compreende o quanto essas pessoas possuem uma forma de pensar diferente e buscam se adequar a elas, apontando a importância da formalização e regularidade para o sucesso do empreendimento.

O advogado de startups precisa ser mais que um profundo conhecedor da técnica jurídica, precisa entender de pessoas, de risco e de estratégia, pois ele terá que invariavelmente fazer com que essa realidade tão técnica seja traduzida para a "língua dos negócios" e vai precisar, ainda, buscar a solução mais rápida e efetiva para o seu cliente, dentro da legalidade e de um sistema pensado de forma por demais burocrática.

O processo para a criação de uma startup obedece a um encadeamento lógico, dividido em fases, qual seja: ideação, validação, tração e escala.

A ideação é quando o indivíduo ou grupo de indivíduos tem uma ideia e desejam desenvolvê-la, como já dito, pode ser um produto ou serviço novo ou renovado, a ideia inicial precisa, contudo, ser alvo de intensas pesquisas de mercado, a fim de saber se aquilo que se pretende vender teria um mínimo de aceitação por parte do público em geral.

Nesse ponto, a sociedade empresária ainda não existe, estando somente, como o próprio nome indica, no campo das ideias. Logo, não possui, ainda, implicações jurídicas. Ao final desse processo espera-se que o empreendedor tenha criado um conceito e que esse conceito tenha um projeto de negócio, com um amplo conhecimento do seu mercado.

Quando a ideia já está mais amadurecida, quando passa de uma mera ideia para um projeto "no papel" que se pretende efetivar é que surge o primeiro desafio para os empreendedores, que é: como vou fazer contato com o mundo externo sem "entregar" a minha ideia a alguém que poderá executá-la?

Surgem preocupações ainda a respeito da relação entre os sócios, p. ex., "se alguém quiser sair depois que o projeto começou, como devemos proceder? E, ainda, "como fazer para contratar alguém que tenha uma determinada expertise que não temos se não possuímos recursos?”. 
Procuram, portanto, uma segurança que só os instrumentos jurídicos podem possibilitar, nesse caso, os contratos de confidencialidade e de vesting (que, mesmo sendo um tema pouco explorado no Brasil da perspectiva acadêmica, é amplamente conhecido e utilizado no meio empreendedor).

O contrassenso se impõe, pois não há juridicamente nenhuma organização, mas a necessidade de captar e reter, faz com que exista algo pré-definido em termos de percepção futura de lucros. Desde então, portanto, precisa-se de uma boa governança.

A validação, por seu turno, é conhecer quem é o seu cliente, qual o nicho de mercado em que ele se encontra, quem é a sua persona ${ }^{4}$.... Mas não é só isso, precisa-se saber como chegar a esse público, como fazê-lo conhecer a existência do seu produto/serviço e, ainda mais importante, como despertar o desejo de compra.

Nessa fase é muito comum a elaboração de pesquisas, entrevistas e outros tipos de imersão que se dispõe a mapear as necessidades e carências do mercado que se pretende atingir. Esse é o ponto em que se encontra a solução, e com a solução a forma de venda.

A validação não necessariamente importa na entrega ao mercado do produto ou serviço, ainda que em fase de teste, podendo restringir-se as pesquisas e entrevistas acima citadas.

Contudo, costuma ser o momento em que o MVP (produto minimamente viável) começa a rodar, ou seja, coloca-se de fato o produto ou serviço no mercado para perceber a sua aceitação. O que faz com que os empreendedores comecem o negócio de fato, em fase de testes, sem qualquer regularização ou formalidade.

Algo totalmente comum ao mundo empreendedor e totalmente na contramão do que a técnica jurídica reputa como o correto a ser feito, posto que segundo os preceitos do artigo 967 do Código Civil, in verbis: "É obrigatória a inscrição do empresário no Registro Público de Atividades Mercantis da respectiva sede, antes do início da sua atividade".

Por outro lado, a LC n $\mathrm{n}^{\circ}$ 167/2019, em seu artigo 60-A, $\S 2^{\circ}$ traz a possibilidade da experimentação provisória, de forma diferente do que traz o Código Civil, conforme pode-se ler:

\footnotetext{
${ }^{4}$ Conceito de cliente ideal.
} 
$\S 2^{\circ}$ As startups caracterizam-se por desenvolver suas inovações em condições de incerteza que requerem experimentos e validações constantes, inclusive mediante comercialização experimental provisória, antes de procederem à comercialização plena e à obtenção de receita.

Nesse mesmo sentido, a Medida Provisória $n^{\circ}$ 881/2019, em seu artigo 3º, VII, in verbis:

VII - implementar, testar e oferecer, gratuitamente ou não, um novo produto ou serviço para um grupo privado e restrito de pessoas maiores e capazes, que se valerá exclusivamente de propriedade privada própria ou de terceiros consensuais, após livre e claro consentimento, sem requerimento ou ato público de liberação da atividade econômica, exceto em hipóteses de segurança nacional, de segurança pública ou sanitária ou de saúde pública, respeitada a legislação vigente, inclusive no que diz respeito à propriedade intelectual;

Ambas permissões legais sustentadas por estes novos diplomas, auxiliam o empreender no processo de validação que a sociedade empresária pode receber sua primeira rodada de investimento, permite que esta consiga "provar" ao mercado o valor do seu produto ou do seu serviço, sem o efetivo comprometimento com a constituição de uma sociedade empresária que poderia não vingar.

Outra implicação jurídica importante deve ser citada, tendo em vista que os processos de investimento são relativamente criteriosos e não investirão em um negócio com um mínimo de organização e possibilidade mínima de prejuízos, muitas startups perdem investimentos na fase de devida diligência (due diligence) que levam em consideração o quadro societário, segmento, local de atuação, entre outros.

A prática mostra que, em razão de não se ter certeza acerca do sucesso ou não da empreitada, os empreendedores colocam o produto ou serviço no mercado, sem a formalização de nenhuma sociedade empresária ou regular. Aqui temos um primeiro ponto de alto risco aos empreendedores.

A tração, é considerado o último momento de uma startup antes de estar consolidada no mercado. Isso é, o produto ou serviço já rodou no mercado, já foi consumido e testado, validado... As pessoas já o conhecem e ele está pronto para ser, de fato vendido, mas está pronto "de direito"? Normalmente, não. 
Caso a startup ainda não tenha recebido nenhum investimento, aqui é o momento em que receberá. É o momento em que se pensa em organizar a casa, da perspectiva jurídica e, às vezes, da perspectiva da gestão também.

Por fim, mas não menos importante, temos a escala, que é o máximo alcance do produto ou serviço, com a perspectiva de crescimento da sociedade empresária. Nessa fase, não há mais dúvida, o conceito empresarial existe e se a pessoa jurídica não está formalizada, por fim, há uma irregularidade técnica, com consequências que podem ser desastrosas e inviabilizar o negócio.

Considerando que as startups são sociedades empresárias que potencialmente estão em fase inicial e fundadas em extrema incerteza, recaímos sobre a já citada área de penumbra do direito, figura que assombra toda e qualquer advogado.

As startups trouxeram o conceito do vesting ao Brasil, tal qual tantos outros, desde a sua forma de se estruturar, até a sua forma de operar no mercado, e simplesmente os colocaram em prática, integrando hoje os usos e costumes empresariais próprios desse nicho.

Toda a inovação em matéria comercial e empresarial é bem-vinda, visto que, funciona, além de tudo, para o fomento e crescimento da economia. Porém, tais inovações jamais podem ser utilizadas de maneira despreocupada com o ordenamento jurídico vigente.

O Direito empresarial, por seu turno, deveria abraçar com mais força e frequência livros e estudos no sentido de aprimorar a sua técnica constantemente para atender as demandas da sociedade que crescem e mudam a todo tempo e, por diversas vezes, não possuem respaldo jurídico e correm à revelia e à margem do que seria o correto.

A busca deve ser sempre pela constitucionalidade das normas aplicadas e segurança jurídica às relações contratuais que se perfazem, a fim de que nosso poder judiciário, já tão sobrecarregado de diversas outras questões, não necessite ocupar-se com mais essa, facilmente sanável no campo normativo.

O Direito privado goza de uma maior liberdade naquilo que se propõe, porém, não está ilimitado, ou seja, não está fora do alcance de fronteiras que devem ser respeitadas, a fim de que se consiga auferir àqueles que desejam constituir uma sociedade a mínima certeza, segurança e previsibilidade que o direito tem que dar aos que se valem dele. 
E é por isso que acreditamos que as startups podem e devem desenvolver-se no Brasil, mas que para isso precisam de respaldo em sua construção e desenvolvimento, respaldo esse que poderá ser dado pelo Direito e por seus diversos mecanismos de prevenção e estruturação tão pouco explorados, estudados e difundidos.

O Artigo 65-A da LC n 167/2019, de uma forma ainda que não muito minuciosa, buscou resguardar não só esses direitos dos empreendedores, como, minimante as relações jurídicas por ele tratadas. Trago, contudo, a crítica ao disposto da lei que afirma a "auto declaração" como elemento caracterizador de startups, posto que não necessariamente essas teriam as características acima citadas no corpo deste artigo.

\title{
GOVERNANÇA CORPORATIVA
}

Como fora exposto acima, o Direito possui mecanismos que permitem, de forma preventiva e estratégica que todos os tipos de negócios se estruturem e cresçam de forma organizada, estratégica e dentro da legalidade, não sofrendo assim os rigores da Lei.

A Governança Corporativa é um desses mecanismos e, segundo a doutrina de André Santa Cruz (2018, p. 353):

\begin{abstract}
"trata-se, basicamente, de um movimento que visa a estabelecer padrões de gestão para os negócios explorados em sociedade, centrados, fundamentalmente nos seguintes princípios: (i) transparência (não se deve apenas cumprir o dever de informação previsto em lei, mas disponibilizar às partes interessadas toda e qualquer informação do seu interesse), (ii) equidade no tratamento entre os acionistas (criação de regras mais protetivas para os minoritários e mais eficientes na prevenção do abuso por parte dos controladores), (iii) prestação de contas confiável (accountability; a prestação de contas deve seguir critérios de contabilidade seguros, eficientes e internacionalmente aceitos), e (iv) responsabilidade corporativa (os administradores/controladores devem zelar pela sustentabilidade das empresas que administram/controlam, visando à longevidade delas e incorporando em suas gestões preocupação de ordem social e ambiental, por exemplo).
\end{abstract}

Em apertada síntese, a governança busca proporcionar boa gestão dos negócios aliada a um constante monitoramento da atuação gerencial dos empreendimentos e pode parecer algo distante da realidade de empreendimentos como startups, mas não o é. 
O momento da boa gestão e da busca pela conformidade se dá (ou deveria se dar) quando se tem uma grande ideia para o desenvolvimento de um negócio. Gestão e conformidade não são preciosismo, tal qual o cumprimento das leis não o é, são obrigações e deveres para todo aquele que pretende crescer e obter sucesso.

A governança se dá por meio de dois sistemas, o outsider system e o insider system, o primeiro é o mais adotado em países onde o mercado de capitais já se encontra consolidado, enquanto que o segundo ocupa-se daqueles em que o mercado de capitais ainda está em estruturação, como é o caso do Brasil.

A diferença primordial desses sistemas está, basicamente em quem ocupa a posição focal da governança, se é ou não o acionista. No insider system tem-se, entre outras características, normas de governança preocupadas com as partes interessadas (materializadas na figura dos stakeholders).

Os stakeholders que são aqueles públicos estratégicos que possuem ou podem vir a possuir interesse no negócio ao ponto de optarem por fazer um investimento nele, ou seja, é aquele que, mediante uma análise de riscos e um processo de due diligence opta por investir seu capital naquele determinado negócio.

Segundo Thomas Clarke (2018, p.19):

Corporate governance is essentially about two things - accountability and innovation. We hear a great deal about accountability, and the principles of accountability are firmly set as the foundations for all the international corporate governance codes practiced around the world. In the focus on the commitment to accountability, which is vital for all corporations for investment and integrity, we have tended to forget about the role of corporate governance in leadership, strategy, and innovation. This role of governance is just as vital for the success of the company in the long term. The board of directors is the epicentre of corporate governance and needs to assure accountability is continuous and robust. But the other major duty of the board of directors is to offer clear leadership in the strategic direction of the company and ensure the company rises to the challenges of competition and change with continuous innovation of its products and processes. This principle was firmly set in the first sentence of the original Principles of Corporate Governance commissioned by the London Stock Exchange (1992) where Cadbury stated "the role of the board is to drive the company forward". 
Como podemos depreender do texto colacionado acima, a inovação não caminha sem a transparência, o accountability e a boa governança. $\mathrm{O}$ caminho de algo inovador não significa que este está afastando-se daquilo que é corretou ou aproximando-se do informal.

No mesmo sentido, vale ressaltar que a boa governança não é uma exigência somente de grandes sociedades empresariais cujos capitais sociais e de giro importam em significativas e estrondosas parcelas.

Com o mesmo rigor e severidade serão analisados a apreciados os pequenos, médios e grandes empresários. A governança corporativa é, e tem que ser, equânime para todos.

Esse o sentido exigido não somente pelo mercado, como pelo legislativo, especialmente após a edição da Lei $\mathrm{n}^{\mathrm{o}}$ 12.846/13, a Lei da Empresa Limpa ou Lei Anticorrupção que, em apertada síntese, responsabiliza objetivamente sociedades empresárias por ilícitos cometidos contra a administração pública (na esfera civil e administrativa), responsabilizando, ainda, seus administradores e agentes de forma subjetiva nas mesmas esferas, sem prejuízo das sanções penais que possam existir.

Não se pode olvidar, em tempo algum, que por serem considerados negócios em fase inicial, auto declarados ou inovadores que, ao fim e ao cabo, não sejam, tais quais todos os outros, negócios jurídicos que se operam entre pares que precisam ter seus direitos minimante resguardados.

Pensa-se aqui, não em uma perspectiva de Estado-Interventor, tão criticado pelos empreendedores, mas um Estado que garante aos seus tutelados a intervenção necessária em caso de necessidade, uma que resguarda o direito econômico, a livre iniciativa e a livre concorrência.

\section{GOVERNANÇA CORPORATIVA E STARTUPS: O QUE ISSO TEM EM COMUM?}

Para compreensão dessa correlação é importante voltarmos aos conceitos trazidos no primeiro tópico acerca das fases pelas quais uma startup passa, por meio do encadeamento lógico, quais sejam: ideação, validação, tração e escala. 
Pretendemos neste trabalho apontar a importância dos mecanismos de Governança e como estes poderiam dar-se em cada uma dessa fases, considerando a realidade deste tipo de mercado e de negócio.

A primeira fase, e talvez a mais importante, é a ideação, que é, como supracitado a fase em que ocorre o desenvolvimento de uma ideia, o momento em que os empreendedores tem uma inquietação que pretendem solucionar por meio de uma solução tecnológica ou não.

Nessa fase, para além da pura concepção do que se pretende efetivamente comercializar ou circular, a compreensão do produto, é o momento em que as pessoas se unem com o propósito do desenvolvimento da ideia, daquilo que poderá se tornar uma sociedade empresária futuramente.

Não há, ainda, atividade de cunho operacional, tão pouco qualquer formalização, e nem haveria por que ter, se considerarmos que temos uma fase de preparação para o nascimento ou não de um novo negócio. Porém, há que se atentar para a existência de uma sociedade de fato entre as partes, da mesma forma que uma concepção inicial de divisão de tarefas e mecanismos de gestão.

Seria interessante, da perspectiva da governança, se, desde já fossem estruturados, de fato, os papéis e as responsabilidades que serão ocupados pelos futuros sócios. Da mesma forma que é recomendável que se especifique normas e formas de contribuição, intensidade e remuneração, além, é claro da futura participação societária do indivíduo.

Outros pontos indispensáveis a essa fase, são a elaboração dos termos de confidencialidade e não competição, os quais garantem a segurança do sigilo de ideia e a impossibilidade de um terceiro de má-fé abandonar o projeto para executar com outro grupo de pessoas, obtendo resultados e frutos de algo sobre o qual não pensou sozinho ou sequer pensou. Além disso, é importante atentar-se a forma de saída do empreendedor e o que acontecerá em caso de descontinuidade do projeto.

Essas questões ficam claramente estabelecidas quando se tem clareza acerca da propriedade intelectual da ideia a qual a sociedade gira em torno, o que, invariavelmente só consegue ocorrer quando existe alinhamento dos sócios no que se refere ao processo de tomada de decisão, que só pode ser construído com o consenso (ou com formas de chegar a ele). 
Todas as questões trazidas acima, bem como outras que podem surgir dessa fase de relacionamento, podem ser elencadas em um documento muito importante para o bem desenvolver da sociedade futura que é o acordo de fundadores (ou founders agreement).

A validação, fase em que ocorre o MVP (minimum viable product) que nada mais é do que o produto ou serviço em fase de teste e, portanto, em contato direto com o mercado e com os seus futuros e potenciais consumidores é totalmente baseada na experimentação.

A fase de testes busca responder incertezas e novas inquietações dos empreendedores, que diferente das incertezas iniciais, agora precisam compreender se aquilo que pensaram (e se a forma como pensaram) é a melhor forma ou, ainda, se é a forma que o mercado quer/procura.

O ideal é que nessa fase a sociedade empresária já esteja formada, ou seja, inscrita e regularizada perante os órgãos competentes, porém, não é isso que a prática indica. Os empreendedores em sua maioria querem certezas antes de "investirem" nos altos custos da constituição de uma sociedade empresária, eles precisam saber se o produto/serviço vai efetivamente "acontecer".

Neste sentido, tem-se atividade operacional, tem-se busca pelos primeiros aportes de capitais e recursos de terceiros e raramente se está, de fato, preparado para efetivar a transação caso consigam.

Nesta fase, portanto, a melhor estratégia de governança é buscar pela constituição e formalização da pessoa jurídica, considerando o risco calculado que é empreender, ou seja, aceitando que pode ser que dê certo e bem suceda, tanto quanto o contrário.

Em paralelo a isto, é importante organizar regramentos e políticas quanto aos direitos e deveres dos sócios, que podem ser materializados pela missão, visão e valores ou pela criação de um código de conduta e políticas internas. Esses mecanismos permitem que as práticas sejam organizadas tanto no que se refere ao relacionamento interno, quanto ao relacionamento com clientes e parceiros estratégicos.

Os controles internos e indicadores-chaves que podem ser percebidos por meio desses mecanismos são diferenciais competitivos de cunho decisivo no momento da concorrência em um edital ou seleção para captação de recursos ou incentivos. 
Na tração, o produto ou serviço já foi testado e aprovado pelo público alvo e agora o desafio é possibilitar que novos clientes sejam conquistados no intuito de aumentar o faturamento e circular de forma sustentável o negócio.

A governança, se bem feita até aqui, permite que sejam estruturadas questões de importância mais destacada, posto que chega-se ao momento de definição de alçadas para a tomada de decisão, de estruturação de conselhos (fiscal, consultivo ou administração) e, ainda de evoluir nas práticas de planejamento e controle do negócio, posto que com o crescimento os controles existentes tendem a ficar obsoletos.

É importante ressaltar que, caso a governança não venha sendo construída passo-apasso, fase a fase, o momento decisivo para a sua implementação poderá não ser o mais oportuno ou agradável e, ainda, deverá percorrer o mesmo caminho.

E o caminho de estruturação inicial, que é aquele que "coloca cada um em seu devido lugar" torna-se potencialmente conflituoso em uma equipe que já cresceu e se desenvolveu de forma desorganizada.

A cultura organizacional é um processo que se constrói e, por vezes, se constrói de forma totalmente perniciosa e disfuncional. Vejam bem, não queremos com isso desestimular a adequação e conformidade ainda que tardias, só precisamos a pontar a desvantagem de optar por isso depois que o negócio já apresenta problemas latentes.

Por fim, mas não menos importante, a fase de escala dá-se em uma sociedade empresária já consolidada e estabelecida. O maior desafio é o crescimento acelerado que o mercado das startups impõe, posto que é crucial que se explore oportunidade de negócios e expansão (eventualmente até em termos geográficos e de equipe) para abarcar-se a demanda que se perfez.

Pode ocorre ainda, do mercado passar a exigir novos produtos ou serviços, ou, ainda a incrementação daqueles já existentes. Vivemos em um mercado sedento por melhora e inovação, e isso significa que o trabalho não acaba, nem quando termina. Quanto mais conhecida uma sociedade empresária, maiores seus desafios frente ao mercado, seus clientes e seus pares.

Eventualmente reestruturações precisam ser feitas, parcerias e acordos. Nada disso se perfaz da melhor forma possível sem organização e segurança. A governança corporativa 
pode e vai garantir maior independência na tomada de decisão segura, mas isso só ocorre quando a mesma atinge um nível de maturidade que só o tempo e prática podem oferecer.

O ideal é que, na fase de escala, as práticas só precisem ser sempre e ainda mais consolidadas, e que possam auxiliar ao negócio nos novos desafios que estão por vir para que este prospere e tenha continuidade.

Fica evidente, portanto, que, tal qual um negócio em fase de desenvolvimento a governança corporativa é um processo que precisa ser construído em paralelo para que possa oferecer os resultados pretendidos e baseados nos princípios e características que possui.

Em seu próprio conceito é relacionada comumente as sociedades anônimas, pelo seu porte, nível de regulação e importância para o mercado, mas não é e nem deve ser restrita a esse tipo societário. A boa governança é e deve ser um dever e uma obrigação de todos.

A transparência, o accountability, a proteção ao minoritário (por meio da equidade) e a sustentabilidade financeira e ambiental são o mínimo que se pode esperar, desejar e exigir de qualquer pessoa ou grupo de pessoas que pretenda fazer circular bens ou serviços frente à tão fragilizada economia que possuímos no país.

É necessária a conscientização dos empresários e empreendedores de que as práticas preventivas e estratégicas custam menos para os seus negócios do que as demandas judiciais, contábeis, entre outras que podem surgir do desleixo e da pouca ou nenhuma preocupação com a conformidade e com a legalidade.

\section{CONCLUSÃO}

Conclui-se, portanto, que a natureza inovadora não só não é um impeditivo a Governança Corporativa, quanto é um convite a mudança estrutural do cenário vivido e experimentado por todos no ambiente negocial.

A inovação pode e deve, por meio de empreendedores que, cansados "das coisas como são", optaram por fazer as coisas de uma forma diferenciada, e essa diferença se destaca e firma em bases sólidas quando acompanhadas por uma verdadeira mudança de comportamento, incluindo o comportamento corporativo. 
Uma boa governança é boa não só para quem empreende, para receber incentivos e investimentos, mas para todo a salvaguarda do empreendedor, enquanto pessoa física e para o bem estar do sociedade que passa a receber melhores serviços e produtos que, por trás do inevitável viés capitalista (no sentido de obtenção de lucros) arrecada com sigo uma efetiva mudança de cenário.

Quando conseguimos mostrar ao mundo que nosso objetivo empreendedor é de fazer a diferença, isso se reverte, invariavelmente, em uma melhor reputação frente ao mercado que, em última forma, faz com que nosso produto ou serviço seja escolhido dentre muitos, ou seja, ser correto, inovador e ter boa governança te possibilitam um destaque no mercado que é, como sabemos, totalmente competitivo e, por vezes, desleal.

Precisamos, à vista disso, congregar as melhores práticas de mercado, a boa governança, com uma atitude que faça sentido (da nossa parte, enquanto pessoa), posto que, estaremos sempre sendo analisados quanto à pertinência de nossa fala e atitude.

Por fim, cumpre ressaltar que, a inovação não se trata somente de tecnologia, mas de mentalidade e de forma de execução de projetos, podemos, portanto, inovar no comportamento ético, combativo frente à corrupção e fraudes, concorrencialmente correto e transformar nossa atividade profissional em uma efetiva mudança social, para que alcancemos o Brasil que almejamos, livre das máculas presente e passadas, e garantindo à nos e aos que nos cercam um lugar melhor de se viver.

\section{REFERÊNCIAS}

CLARKE, Thomas. Governança Corporativa e Inovação: tendências e reflexões - Instituto Brasileiro de Governança Corporativa - Coporate Governance: leadership, strategy and innovation (p. 19). Org.: Carlos Eduardo Lessa Brandao, Joaquim Rubens Fontes Filho, Sergio Nunes Muritiba.

BRASIL. Medida Provisória no 881 de 30 de abril de 2019. Remetida à Sanção.

BRASIL. Lei Complementar no 167 de 24 de abril de 2019. Publicado em: 25/04/2019. Edição 79, seção 1, página 1. Atos do Poder Legislativo.

RAMOS, André Luiz Santa Cruz. Direito empresarial esquematizado. 6. ed. São Paulo: Método, 2018.

RIES, Eric. The Lean Startup: How today's entrepreneurs use continuous innovation to creat radically successful business. S.l: Crown Business, 2011. 
